\title{
Trends in adult complementary education in the modern digital space
}

\author{
Valentina Abraukhova ${ }^{1,{ }^{*}}$ and Anastasiya Zimovetc ${ }^{1}$ \\ ${ }^{1}$ Don State Technical University, Gagarin Sq., 1, 344003 Rostov-on-Don, Russia
}

\begin{abstract}
The paper examines the application of different methods and approaches in teaching adults a foreign language as part of additional education. The authors of the article aim to identify modern trends in the development of additional adult education, ensuring the creation of an optimal educational environment for successful adult instruction in a foreign language. This paper examines the social and psychological characteristics of adult learners. Emphasis is placed on the superiority of active training methods using information and communication technologies. It is concluded that for the most effective realization of the educational potential of a foreign language by adult students in the conditions of additional education, it is necessary for the teacher to combine pedagogical and anagogical models of education using digital technologies.
\end{abstract}

\section{Introduction}

The potential for additional adult education has not been studied in detail, and therefore cannot be used sufficiently and optimally. The purpose of the article is to study trends in the development of additional adult education. Economists are building a further life strategy as a way to overcome successive crises. Pedagogy sees the strategy of human education in the continuity of this process. Information is changing so rapidly that the volume of knowledge is growing exponentially, so the path to "lifelong education" is relevant, where self-study and self-development based on the use of digital technologies are the leading method.

A. Green's studies define the features of continuous education as complimentary or mutually complementary - official (formal), unofficial (non-formal) and informal (informal) education [1].

In modern literature, there is no single approach to determining additional adult education in view of the variety of forms of its implementation: one can find such stable combinations as "adult education" (Federation des adultes, Erwachsenenbildung); continuing education; "further education" (further education, Weiterbildung); "Recurring education" as "part-by-part" education throughout life by alternating learning with other activities, mainly work; permanent education; lifelong education; "lifelong teaching" (lifelong learning, Federation permanente).

\footnotetext{
* Corresponding author: childrenpalace@mail.ru
} 


\section{Materials and Methods}

In Russia, before the appearance of a network of extracurricular educational institutions in the 30. XX century, the term extracurricular education meant "educational activities of public organizations and individuals aimed at satisfying the educational needs of the population," that is, children and adults. Arguing about the meaning of the concept of "extracurricular" E.N. Medynsky in his book "Methods of extracurricular educational work" notes that "if we consider education only the assimilation of knowledge, then division (school and extracurricular) will be wrong, because it is taken out of school, and what in addition to it, but during its stay in it the epithet "extracurricular" not only does not explain anything, but even obscures and is completely superfluous in relation to the word "education." From the recognition of "extracurricular education" is equal to comprehensive development, two highly important consequences arise that the tasks of all institutions for extracurricular education are mainly developing; and that the full system of promoting extracurricular education should be designed so that all sides of the human Self, spiritual and physical, can receive satisfaction[2].

According to the study of I. V. Gavrilova, L. Zaprudnova, when answering the question "What forms of education do you prefer," data were obtained - $67 \%$ of respondents note formal education, $48 \%$ note the possibility of using various forms of education, $53 \%$ for non-formal education, $18 \%$ for informal education [3].

Modern additional adult education is in great demand today. The Federal Law "On Education in the Russian Federation" interprets additional education "as a type of education that is aimed at comprehensively satisfying the educational needs of a person in intellectual, spiritual, moral, physical and (or) professional improvement and is not accompanied by an increase in the level of education" [4].

Supplementary general education programs are divided into general and preprofessional programs and are implemented for both children and adults.

Analyzing the works of O. O. Varlamov, S. I. Zmeev, Y. G. Podkosova, V. V. Selivanov, L. N. Selivanova, E. I. Stepanova [5], we came to the conclusion that an adult has a specific position in relation to the problem of education. Based on these studies, we are interested in the characteristics of an adult as a student: existing life experience in different fields, the need for certain knowledge generates motivation, different levels of mastery of information and communication technologies, increased responsibility, independent implementation of the choice of further forms of education

By analyzing the needs of the labor market, we can come to the conclusion that adult education does not play an insignificant role in meeting demand needs, since today the main criteria are the qualification and competence of employees. Adult education includes: the educational sphere (vocational retraining courses, advanced training courses and others), the cultural environment (circles, various clubs). In addition, there are a huge number of private organizations involved in adult education. As a rule, they are engaged in various projects, work related to civic education and all kinds of social problems[6-7].

However, according to studies in the field of adult education, it is quite difficult for a person to abandon the usual values and professional foundations until he realizes from personal active experience that it is necessary to retreat from some of them in favor of more productive ones. These provisions lead to the fact that in the framework of adult education the problem of finding new and improving old methodological systems and approaches that will lead to increased professionalism of employees and achieve new results is relevant.

The most popular area of additional adult education is the study of foreign languages - the desire to increase their level of knowledge for use in professional activities, expand their horizons, travel and communicate freely, go to live abroad and more [8-9]. 
The most common method of teaching a foreign language to adults is the grammar translation method, when it is necessary to work out a new grammatical rule or it is necessary to learn new lexical units. This has a positive effect on students, since regular repetitive actions do not remove an adult student from the comfort zone. However, this may cause the inability to respond and adequately perceive regularly changing aspects of oral speech. It is worth noting that in the framework of the modern educational process, the communicative method of teaching is widely used, this method is radically different from the previous one. Therefore, teaching adults according to a new program for them, it is worth periodically applying traditional, that is, their usual methods and forms of teaching. Training formats such as: debating, gaming, etc., have been widely used. Having a rich life experience as an established and well-established model of mental behavior and the formation of the character of an adult often have a negative impact on the learning process. Very often, an adult student is unable to accept the judgments and characteristic aspects of representatives of a different mental system. This is due to the fact that an adult has his own formed understanding of the life system and its surrounding reality. Foreign speech is a way of expressing the thinking of a different mental system and its understanding is hardly perceived by adult learners [10].

An important principle in adult education is an individual approach. When implementing this principle at the initial stages, questionnaires, testing, conversations and various kinds of surveys play an important role. As part of the study of a foreign language, special attention should be paid to primary testing, this type of activity will help to determine the level of knowledge of the AI and set the right direction for subsequent work. Determining the level of proficiency in a foreign language contributes to a more productive conduct of classes and a competent curriculum aimed at a certain student. It is worth noting that in practice, when teaching an adult, there is a certain tendency to "underestimate" one's own knowledge and skills. This trend is observed during an oral interview and is manifested in the fact that students deliberately underestimate their level of IA possession. As a rule, this is due to the uncertainty and inability to use the existing knowledge base. Taking into account the results of surveys, tests and analyzing the social status and professional activity of a person, the andragogue can draw up a socio-psychological portrait of the student. The results of these tests and surveys allow us to correctly draw up a training program that can lead to a more productive absorption of the material, since it, in turn, is compiled taking into account the individual characteristics and needs of an adult student.

An adult learner needs to understand the reason and meaning, structure and laws of constructing the heard material and all processes taking place around it, in addition, for better assimilation, analogies must be drawn between the native language and the student. The lack of understanding of the grammatical structure and not the awareness of logical semantic models leads to internal conflict and the non-acceptance of new knowledge. Therefore, we can conclude that an adult does not need only mechanical learning and repetition to master new material in a foreign language. When preparing the lesson plan, the andragogue teacher must take into account these features. On the basis of the above, we can conclude that the andragogue should not teach an adult student and authoritarian dictate his conditions of study. After analyzing the characteristics of the student, the andragogue should contribute to the choice of the most effective way to study AI and provide competent support during training [11].

The principle of systemic learning for an adult student is essential. It needs specificity and clarity when mastering IA. The student needs to know the general principles of work, understand the structure of the lesson, and possess general information related to methodological materials. The goal of the teacher is a competent and logical construction of the course, understandable to the student, providing the necessary information about the organization of the educational process, determining the final goal. Also, the andragogue 
teacher needs to carefully monitor the compliance of the goals and content of training with its form, method, tool and evaluation of results. An adult assimilates the material and feels confident only when he sees the exact learning scheme and presents the final result [12].

The principle of the need for learning results is related to the specific needs of an adult student. An andragogue teacher removes all materials in which there is no direct interest, leaving only the material that meets the student's specific needs. This is due to the lack of time in a modern adult. As a rule, students need to achieve a certain level of proficiency in a foreign language in a short time. This feature is taken into account in the preparation of the curriculum. We also revealed that an adult student needs to constantly test and test his own knowledge at the end of each training block. This allows him to pro-analyze his successes and see progress, which in turn motivates further training

The basic idea of learning through an andragological approach is to develop tailored programmes to meet the needs of adult learners. Over the years, this has led to the fact that training covers many areas, such as foreign language for academic purposes, foreign language for professional purposes, for medical purposes, for business purposes, for legal purposes, for sociocultural purposes and for professional purposes in industry, transport, agriculture.

According to the andragological approach, students are ready for learning as long as they feel the need for it. Therefore, they need to clearly understand the goals and objectives of the course. They should see how content, learning and goals help them achieve those goals [13-14].

The second conclusion is related to training strategies that should be as individualized as possible. The anagogical approach to learning implies that the individual characteristics of students should be fully taken into account.

One of these vital characteristics is how people enjoy learning. To meet this need, teachers must determine the preferred ways of educating students and compare them with educational tasks.

The third conclusion emphasizes the importance of the experience of students as a rich resource. If students realize that their experience can be used for educational purposes, they will have higher self-esteem and greater motivation.

To achieve this, different training methods can be used. These include panel discussions, problem-solving activities, group projects and case studies.

This enables adult students to engage in interpersonal communication, allowing them to share their experiences. When students realize that their existing knowledge and experience contribute to their own development, they are more likely to play an active role in learning. They will also take responsibility for educating their fellow students, which increases mutual responsibility.

In andragogy, learning must be genuine. For this to happen, students must be able to apply knowledge in real-world situations at once. Therefore, cognitively complex situations created in the framework of training should involve students in a communication process that requires the active use of the target language.

This can be facilitated by the use of task-based learning, which creates opportunities for "social interaction between students as a source of contribution and a means of acquisition and includes the harmonization of meaning, communicative strategies and communicative effectiveness" [15].

A special role in the learning process is played by the principle of dialogue, which in its humanization is opposed to the principle of authoritarian learning. Knowledge obtained in foreign language classes, and lexicology in particular, is based on the individual characteristics of students (characteristic of the processes of thinking, perception, memory, motivation), while the student independently receives knowledge during the learning 
process, when the teacher guides him, going through the entire path of study with the student.

This approach is closely related to the implementation of the principle of clarity, when reference schemes and algorithms are used in the training process. With this approach, students invariably become in a situation where they must independently understand the learning process and express their own opinions on the topic. Knowledge generation is usually based on discussion.

Taking into account the latest technologies and the new information and educational sphere, foreign language education has become effective and outside the natural environment. The implementation of education has become possible, since forums, distance learning, social networks, applications and other types of modern communication are able to organize communication that occurs with native speakers or with highly qualified specialists without leaving home. Also, using Internet resources, the student is able to model his learning environment, bringing it as close as possible to authentic. This effect can be achieved using multimedia technologies.

The modern period of society development is characterized by the strong influence of information technologies, which penetrate into all spheres of human activity, called the phenomenon of digitalization. Therefore, digital technology becomes as necessary as the ability to read and count.

Also, the adult's interest in learning English is due to the fact that currently English contributes to successful professional and communicative activities.

\section{Results}

According to official EU data, in European countries 31\% of the population aged 55 years and older, $39 \%$ of the population aged 40 to 54 years, $52 \%$ of people aged 25 to 39 years speak a foreign language. Based on the data presented above and the requests of the labor market, we can say that teaching foreign languages plays an important role and occupies one of the key places in the educational system of most leading countries, including Russia.

To learn English more effectively, students need to be interested. To identify additional personal information about students, a questionnaire was proposed, where it was necessary to write about their hobbies, plans for the future.

Table 1. Selection of topics by interest

\begin{tabular}{|l|l|l|}
\hline Learner & Favourite school subjects Off-hour clases & Free time Profesions \\
\hline Learner A & $\begin{array}{l}\text { PE Football Listen to the music, play with } \\
\text { friends }\end{array}$ & Don't know \\
\hline Learner B & $\begin{array}{l}\text { EnglishLiterature No Read books, meet friends, } \\
\text { play }\end{array}$ & Journalist \\
\hline Learner C & $\begin{array}{l}\text { History Music } \\
\text { English Singing lessons Cinema, museum }\end{array}$ & Pedagogy \\
\hline
\end{tabular}

After all the data were collected, we committed the crime of writing an English language program for students with a level of knowledge of English A2 (Pre-ntermediate). The duration of the program is six months, taking into account the conduct of two individual lessons per week for 60 minutes. The training program contains a set of topics on vocabulary and grammar, includes tasks for auditing, reading, grammar of the English language, as well as written (essays, writing to a friend) and oral (compiling a monologue/dialogue) tasks. After writing the basic part of the program, which lists all the necessary topics, we adapted it for each individual student, taking into account their age, as 
well as interests and hobbies. By adding tasks with students interested in topics, the goal of constant interest in our subject is achieved.

It is worth noting that at each stage of learning English, students pass the same topics, but the higher the level, the greater the range of knowledge covered. In this study, we pay special attention to methods for studying new vocabulary and grammar.

Also, we consider it necessary to indicate that during the training process it was revealed that student A has good visual memory. When teaching it, visualization (bright colors, pictures) is important. After all, remembering, for example, a recently learned word, he relies on a picture that appeared in his head. Students B and C have better developed mechanical memory, so learning a new word, it will be better to write it into a dictionary, give a detailed definition and description.

Each lesson lasts 60 minutes and is divided into 3 parts:

1. Warm up or warm up. It is known that the process of switching from the native language to the studied foreign language does not occur automatically. The student needs to tune in the atmosphere of the English language, connect his spoken and hearing aids.

2. The main part of the lesson. Usually at this time, the teacher checks homework, analyzes errors (if any), and also explains a new topic or anchors recently passed material with the student.

3. Conclusion. At this stage, the passed material is fixed, for example, in a game form using digital technologies.

The results obtained during the study indicate that interest in various forms of adult education is growing both from the side of science and from practitioners, especially in the era of the information space, in the context of the creation of network pedagogical communities and many other factors.

\section{Discussion}

Digital technologies are at this point in time key and predominant in the field of education in general and on the example of teaching foreign languages in particular. Total employment and lack of free time on the one hand and the request for compact, convenient comprehensive training on the other have led the field of education to the need to provide adult education services and formats for all cases.

The student can have instant access to authentic resources, perform tasks and communicate with participants in the educational process anywhere and at any time. Mobile technologies help the best educate and organize group and individual training [16]. Subject to corrective course construction in general and tasks in particular. This provision corresponds to a competently oriented concept of education. However, the widespread use and uncontrolled use of mobile applications can lead to poor-quality and spontaneous consumption of information, which in turn makes the training process complex, not structured and leads to minimal benefits.

It should also be noted that ICC (information and communication competence) is also based on a competently built training course

From the experience of recent years, I can talk about programs such as Google class, which has in its structure both the space for shaping the course and administration, as well as building tasks based on the proposed programs. More than 60 programs and applications are integrated into your classroom. Technologies such as:

- Applications for creating mental maps (Coogle)

- Online Interactive Process Visualization Boards (Padlet)

-Timeline

-Create multi-media presentations (Moovly, Google jamboard,)

- Testing and collaboration on projects (google forms, google docs) 
-Screen-o-matic screencasts, video cameras and posts

- Create a word cloud (Wordcloud)

-Training videos (TEDs TALK, Edpuzzle.BBC historical)

\section{Conclusions}

The topic of using digital technologies in training is now relevant. The results of the study on this topic have already been reflected by the authors in Scopus articles: the content of multimedia orientations of students was investigated, articles on education and teaching technologies (Scopus) were analyzed, continuous education was studied [17-19].

All the above resources undoubtedly enrich interest and give a new vector of development in the motivation of the student, as well as clarify with each lesson a convenient method of submitting information, and its introduction into the training process.

The particular popularity of the direction of games, fantasy books and historical angles were also perceived in the entertainment environment of online games, in turn, the games gave another platform for language training. Online games have turned this current into a whole community of people connected by one interest in the game, but having different social, age and personal interests.

VR - virtual reality and its accompanying industry has become one of the most commercially successful and dynamically developing during the pandemic and recent years.

Departing from the concept of fashion and relevance, we still cannot but note the most important aspects that are associated with promoting and strengthening the position of remote, online, mobile training.

Despite all the difficulties with universal access to the Internet and mobile devices, the process is inexorable, and the data show that every year Internet speed and accessibility technologies in our country are improving. However, the launch of any course, training program or even a typical task must be strictly worked out and has not only accurate focus, content and convenience, do not forget about the administration process in training and knowledge testing. And as experience, motivation and feedback shows, the response to execution and its evaluation play an equally important role than the program itself and its content.

\section{References}

1. https://www.researchgate.net/publication/224767020_Lifelong_Learning_What_does_i t_Mean (last accessed 2020/11/12)

2. V.V. Abraukhova, Opportunities for the establishment of additional education as an environment for the creative development of children and adults, Pech Pedagogicheskiy zhurnal 10, 79-87 (2020) DOI: 10.34670/AR. 2020. 47. 33.032

3. I.V. Gavrilova, L.A. Zaprudnova, Formal, informal and informal models of education, Young scientist 10, 1197-1200 (2016) https://moluch.ru/archive/114/29876/ (last accessed 2020/11/22)

4. Federal Law "On Education in the Russian Federation" from 29.12.2012 N 273-FZ (ed. From 08.12.2020).

5. T.E. Zmeeva, Teacher of a foreign language at a university: teacher or andragog? Almanac of modern science and education, 11, 96 - 101 (2011)

6. M. Mihaela, Using Cybergogy and Andragogy Paradigms in Lifelong Learning, Procedia, Social and Behavioral Sciences, 116, 4722-4726 (2014) 
7. D.L. Pennington, Emic, etic, and andragogy: The contributions of Nobleza AsunciónLande to intercultural communication International Journal of Intercultural Relations 36, 770-779 (2012)

8. B. Gjestvang, S. Høye, B.A. Bronken, Aspiring for competence in a multifaceted everyday life: A qualitative study of adult students' experiences of a blended learning master programme in Norway, International Journal of Nursing Sciences 8, 71-78 (2021) https://doi.org/10.1016/j.ijnss.2020.11.001

9. J.A. Henschke, An International Perspective on Reorienting Traditional Higher Education Institutions toward Lifelong Learning, Procedia - Social and Behavioral Sciences, 142, 36-46 (2014) https://doi.org/10.1016/j.sbspro.2014.07.585

10. A. Reid, J. Cook, C. V. Caren, B. Scheepers, Developing management effectiveness: The nexus between teaching and coaching, The International Journal of Management Education, 18, 100334 (2020) https://doi.org/10.1016/j.ijme.2019.100334

11. C. Tønseth, Situational Triggering Factors - Adult's "Readiness to Learn"-connected to Certain Life-stages and Age? Procedia - Social and Behavioral Sciences, 174, 33303341 (2015) https://doi.org/10.1016/j.sbspro.2015.01.1001

12. A.A. Holland, Effective principles of informal online learning design: A theorybuilding metasynthesis of qualitative research, Computers \& Education 128, 214-226, (2019) https://doi.org/10.1016/j.compedu.2018.09.026

13. C. Cocquyt, C. Zhu, A.N. Diep, M. De Greef, T. Vanwing, Examining the role of learning support in blended learning for adults' social inclusion and social capital, $\begin{array}{lllll}\text { Computers } \quad \& \quad \text { Education } & \text { 142, } & 103610 & \text { (2019) }\end{array}$ https://doi.org/10.1016/j.compedu.2019.103610

14. L. Zhuhadar, O. Nasraoui, R. Wyatt, "Knowledge Mining for Adaptive Multimedia Web-based Educational Platform", Book: Technology Enhanced Learning: Best Practices (Idea Group, 2008)

15. E. Ya Egorchenkova, Formation of self-educational competence in a foreign language among students of a non-linguistic economic university, Foreign languages at school, 378-385 (2013) https://doi.org/10.1016/j.chb.2012.09.009

16. M. Cozma, The Challenge of Teaching English to Adult Learners in Today's World, Procedia - Social and Behavioral Sciences, 197, 1209-1214 (2015) https://doi.org/10.1016/j.sbspro.2015.07.380

17. V.V. Abraukhova, T.I. Vlasova, N.A. Mamchits, E.I. Egorova, Content of multimedia orientations of students: risks and ways of their pedagogical overcoming within the framework of social partnership, Electron. SHS Web of Conferences, 70, 6 (Trends in the Development of Psycho-Pedagogical Education in the Conditions of Transitional Society (ICTDPP-2019), (Rostov-on-Don, Russia, November 22-23, 2019).

18. V.V. Abraukhova, T. Tavukchu, A.M. Kalimullin, A.V. Litvinov, N.N. Shindryaeva, N.M. Abdikeev, Analysis of Articles on Education and Training Technologies (Scopus )/Electr. International Journal of New Technologies in Training (iJET) 15, 108-120 (2020)

19. V.V. Abraukhova, T.I. Vlasova, A.S. Zimovetc, Continuity of natural science education as a condition for training specialists of the agrarian sector of the economy, /https://www.e3scofeences.org/articles/e3sconf/abs/2020/35/contents/contents.html,htt ps://doi.org/10.1051/e3sconf/202017515005 (last accessed 2020/11/22) 